\section{Immunocytochemical detection of dentin matrix proteins in primary teeth from patients with dentinogenesis imperfecta associated with osteogenesis imperfecta}

\author{
G. Orsini, ${ }^{1}$ A. Majorana, ${ }^{2}$ A. Mazzoni, ${ }^{3}$ \\ A. Putignano, ${ }^{1}$ M. Falconi, ${ }^{4}$ A. Polimeni, ${ }^{5}$ \\ L. Breschi ${ }^{4}$
}

'Department of Clinical Sciences and Stomatology, Polytechnic University of Marche, Ancona

2Department of Medical-Surgical Specialties, Radiologic Sciences and

Public Health, University of Brescia

${ }^{3}$ Department of Medical Sciences,

University of Trieste

${ }^{4}$ Department of Biomedical and

Neuromotor Sciences, University of

Bologna

${ }^{5}$ Department of Oral Sciences,

Prosthodontics Unit, La Sapienza

University of Rome, Italy

\section{Abstract}

Dentinogenesis imperfecta determines structural alterations of the collagen structure still not completely elucidated. Immunohistochemical analysis was used to assay type I and VI collagen, various non-collagenous proteins distribution in human primary teeth from healthy patients or from patients affected by type I dentinogenesis imperfecta (DGI-I) associated with osteogenesis imperfecta (OI). In sound primary teeth, an organized well-known ordered pattern of the type I collagen fibrils was found, whereas atypical and disorganized fibrillar structures were observed in dentin of DGI-I affected patients. Expression of type I collagen was observed in both normal and affected primary teeth, although normal dentin stained more uniformly than DGI-I affected dentin. Reactivity of type VI collagen was significantly lower in normal teeth than in dentin from DGI-I affected patients $(\mathrm{P}<0.05)$. Expressions of dentin matrix protein-1 (DMP1) and osteopontin (OPN) were observed in both normal dentin and dentin from DGI-I affected patients, without significant differences, being DMP1 generally more abundantly expressed. Immunolabeling for chondroitin sulfate (CS) and biglycan (BGN) was weaker in dentin from DGI-I-affected patients compared to normal dentin, this decrease being significant only for CS. This study shows ultrastructural alterations in dentin obtained from patients affected by DGI-I, supported by immunocytochemical assays of different collagenous and non-collagenous proteins.

\section{Introduction}

Type I collagen is the major extracellular matrix protein in dentin comprising $85-90 \%$ of the organic matrix. Type I collagen is a triple helix containing two alpha 1 and one alpha 2 polypeptides, which are expressed from COL1A1 and COL1A2. Mutations in these genes cause osteogenesis imperfecta (OI), an autosomal dominant form of brittle bone disease. ${ }^{1}$ OI is usually classified on the basis of clinical and radiologic criteria in 4 types. ${ }^{1}$ Each of the 4 types of $0 \mathrm{I}$ is further subdivided on the presence or absence of the developmental dental defect known as dentinogenesis imperfecta (DGI), in which three types can be recognized: DGI-I, DGI-II, and DGI-III. ${ }^{1-3}$

DGI-I is the dental phenotype recorded in patients affected by OI, which has been noted to be OI types III and IV in approximately $80 \%{ }^{1}$ Clinically, teeth show marked discoloration, tendency of normal enamel to crack off, bulbous crowns, short roots and attrition in both the deciduous and permanent dentitions. ${ }^{3}$ Pulpal obliteration occurs soon after eruption or prior to tooth eruption, ${ }^{3}$ varying, even within a single individual, from total pulpal obliteration to normal pulp dimensions. ${ }^{1}$ Although previous studies largely discussed on the genetic changes occurring in $0 \mathrm{I}$, little is known on phenotype changes of dentin structure and ultrastructure in patients also showing DGII. ${ }^{4,6}$ Dentin of DGI-I affected patients has been reported to show irregular texture of dentinal areas, abnormal number and structure of dentin tubules, areas of atubular dentin, ${ }^{5}$ and ultrastructural abnormalities in the appearance and organization pattern of collagen fibers. ${ }^{4}$ Immuno-electron microscopy studies have assayed reactivity for different types of collagen, showing presence of type VI collagen and decreasing of type I collagen expression in DGI-I affected dentin. ${ }^{2,6}$ Moreover, DGI-I affected patients displayed reactive zones for the non-collagenous protein fibronectin, alternating layerwise or concentrically with non-reactive ones. ${ }^{2}$

Non-collagenous proteins (NCPs) have been shown to play fundamental roles in actively promoting, controlling, and regulating fibrillogenesis, crystal growth, and mineralization during dentinogenesis. ${ }^{7}$ However, no recent immunocytochemical studies have defined whether there is a correlation among the different alterations described in collagenous and non-collagenous dentin components in DGI-I affected patients. Among the NCPs, special
Correspondence: Prof. Lorenzo Breschi, Biomedical and Neuromotor Sciences, DIBINEM, University of Bologna, via San Vitale 59, 40125 Bologna, Italy.

Tel. +39.051.2088139 - Fax: +39.051 .225208 .

E-mail: lorenzo.breschi@unibo.it

Key words: Osteogenesis imperfecta, dentinogenesis imperfecta, immuno-electron microscopy, collagen, non-collagenous proteins.

Acknowledgments: the authors report no conflict of interest and wish to thank Mr. Aurelio Valmori (University of Bologna) for photographical assistance and Dr. Rosa Curci (IOR, Bologna) for laboratory processing. Dr. Elena Bardellini (University of Brescia) and Dr. PierCarlo Brunelli (Spedali Civili, Brescia) are also kindly acknowledged for helping during Ethical Committee approval and management of young patients affected by osteogenesis imperfecta, respectively. The study was founded with grants from MIUR (Italy): FIRB RBAP1095CR and PRIN 2009SAN9K5 to L. Breschi.

Received for publication: 2 April 2014.

Accepted for publication: 10 November 2014.

This work is licensed under a Creative Commons Attribution NonCommercial 3.0 License (CC BYNC 3.0).

(C) Copyright G. Orsini et al., 2014

Licensee PAGEPress, Italy

European Journal of Histochemistry 2014; 58:2405 doi:10.4081/ejh.2014.2405

interests have been given to some small leucine-rich proteoglycans (including chondroitin 4/6 sulphate (CS)-rich decorin and biglycan), and to certain glycoproteins (including the prominent members of the SIBLINGs family: dentin matrix protein-1 and osteopontin), during predentin fibrillogenesis and dentin mineralization, respectively. ${ }^{89}$

Therefore, the aim of the present study was to elucidate morphological alterations of defective dentin in patients affected by DGI-I and OI, by ultrastructural and immunocytochemical analyses. Type I and VI collagen, dentin matrix protein-1 (DMP-1), osteopontin (OPN), biglycan (BGN), and chondroitin sulfate (CS) were investigated. The tested hypothesis was that no correlation exists between the ultrastructural abnormalities of dentin affected by type I DGI (associated with $0 \mathrm{I}$ ) and defective production of both collagenous and NCPs.

\section{Materials and Methods}

All reagents were purchased from Sigma Aldrich (St. Louis, M0, USA), unless otherwise specified. 
Ten primary teeth exfoliated from five patients affected by DGI associated with OI were used in this study. Five human primary teeth exfoliated were used as controls. The subjects had a mean age of 6.1 years. The consent form and experimental protocol was approved by the Ethics Committee of the "A0 Spedali Civili" of Brescia (Italy). Following extraction, teeth were cut with a low speed diamond saw and sectioned to obtain $1 \mathrm{~mm}$-thick dentin disks. The disks were immediately fixed in $4 \%$ paraformaldehyde and $0.1 \%$ glutaraldehyde buffered with $0.1 \mathrm{M}$ sodium cacodylate, at $\mathrm{pH} 7.2$ overnight at $4^{\circ} \mathrm{C}$.

\section{Immunocytochemical procedure}

After fixation, disks were rinsed for $1 \mathrm{~h}$ in $0.1 \mathrm{M}$ cacodylate buffer $\mathrm{pH} 7.4$, and decalcified using $4.13 \%$ EDTA for three months at $4^{\circ} \mathrm{C}$. Specimens were then extensively rinsed with $0.1 \mathrm{M}$ sodium cacodylate buffer, dehydrated in graded concentrations (50, 70, 90, 95 and $100 \%)$ of ethanol and embedded in LR White resin (London Resin, Berkshire, UK). Semithin sections $(1 \mu \mathrm{m})$ were cut with glass knives on a Reichert Jung Ultracut E ultramicrotome and stained with toluidine blue. Selected areas of the specimens were trimmed for ultra thin sectioning $(80 \mathrm{~nm})$ using a diamond knife. Sections were mounted on Formvar carbon-coated nickel grids.

Grid-mounted tissue sections were processed for immunocytochemical labeling using the following primary antibodies: rabbit anti-type VI collagen (Fitzgerald Ind. Int., Acton, MA, USA) and mouse anti-type I collagen (C2456, Sigma Aldrich), rabbit anti-DMP1 (LF-160, generously donated by Dr. Larry Fisher, National Institute of Dental and Craniofacial Research, Bethesda, MD, USA), rabbit anti-OPN (LF-166, generously donated by Dr. Larry Fisher), mouse anti-CS (CS-56, Sigma Aldrich), rabbit anti-BGN (LF-51, generously donated by Dr. Larry Fisher) as previously reported. ${ }^{8,9}$ In brief, sections were immersed in $0.05 \mathrm{M}$ Tris $\mathrm{HCl}$ buffered solutions (TBS) at $\mathrm{pH} 7.6$, pre-incubated with normal goat serum for $30 \mathrm{~min}$, and incubated overnight with each on of the above mentioned primary antibodies at $4^{\circ} \mathrm{C}$. Gold labeling was performed using anti-mouse IgG secondary antibodies conjugated with 15-nm nanoparticles and goat anti-rabbit IgG secondary antibodies conjugated to 15 $\mathrm{nm}$ gold nanoparticles (British BioCell International, Cardiff, UK) diluted 1:100 in $0.02 \mathrm{M}$ Tris $\mathrm{HCl}$ buffered solutions (TBS) at $\mathrm{pH}$ 8.2. After labeling, grids were rinsed and stained with $4 \%$ uranyl acetate and lead citrate for examination with a Zeiss EM 109 electron microscope.

Controls consisted of sections incubated a with a secondary antibody only; and substituting the primary antisera with non-immune serum. For each antigen, gold particle density was calculated in 20 different areas corresponding to 20,000X magnification (area of 3898 $\mu^{2}$ ) using the Philips CM10 microscope and Megaview software system (FEI Company, Eindhoven, The Netherlands). Statistical differences were assessed by Student $t$-test $(\mathrm{P}<0.05)$ and it was performed with GraphPad Prism 5.0 software (San Diego, CA, USA).

\section{Results}

Structural and ultrastructural features and expression patterns of various collagenous and non-collagenous proteins in sound primary teeth and teeth from patients affected by DGII, associated with OI were assayed. Light microscopy showed paucity and irregularity of tubules in the dentin of DGI-I affected patients (Figure $1 \mathrm{a}, \mathrm{b}$ ).

Ultrastructural examination showed the dentin of DGI-I affected patients with thick, sparse and a few lax curvy bundles of crossstriated collagen fibers, whereas uniform dense collagen pattern was recognizable in sound primary dentin (Figure $1 \mathrm{c}, \mathrm{d}$ ). Table 1 summarizes the quantification of the labeling for the collagenous and non-collagenous
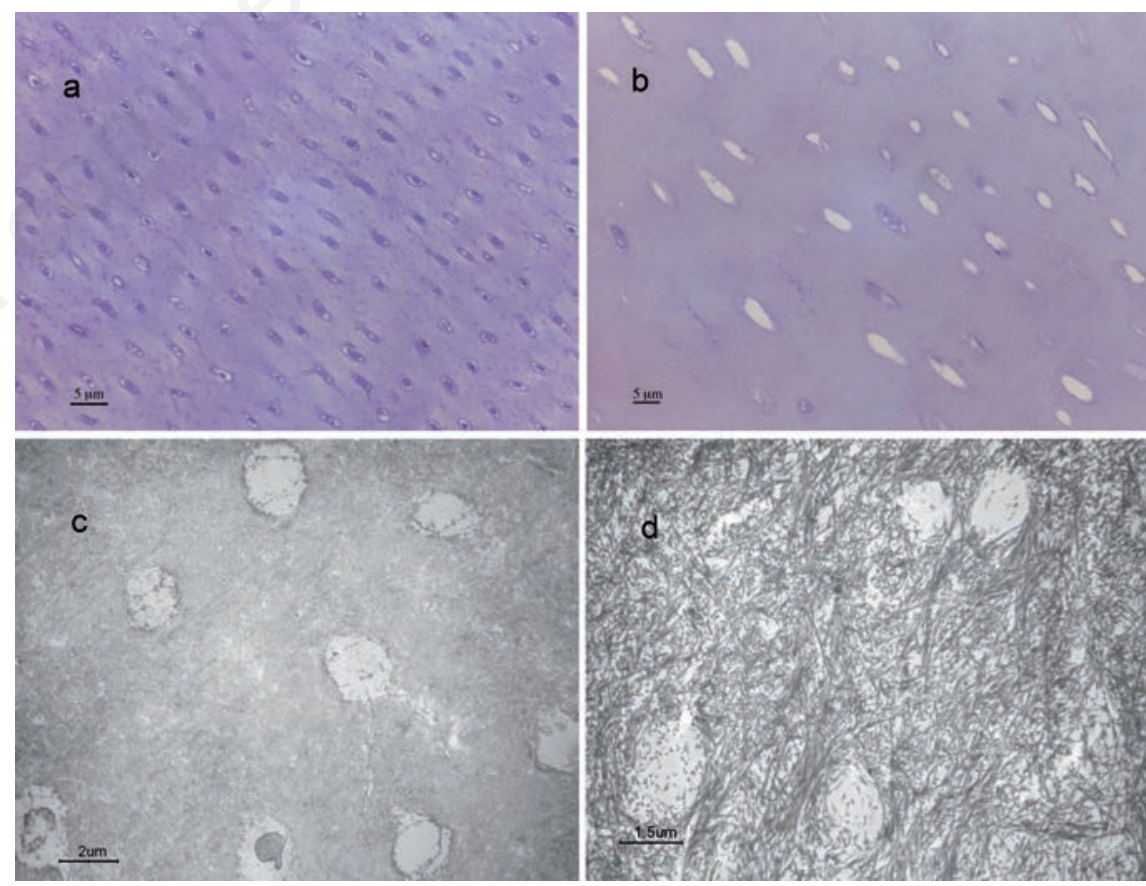

Figure 1. Light micrographs showing dentin of a) exfoliated sound primary teeth, presenting an uniform tubular structure and b) type I dentinogenesis imperfecta (DGI-I) affected teeth, presenting paucity and irregularity of tubules, toluidine blue staining. c,d) Transmission electron micrographs showing: c) normal dentin with uniform dense collagen pattern and tubular structure; d) DGI-I affected dentin characterized by a collagen fibrillar immature pattern not well arranged in lax curvy bundles. 


\section{Discussion}

The tested hypothesis that there is no correlation between the ultrastructural findings in dentin from DGI-I affected patients and defective expression patterns of collagenous and NCPs is partially rejected, since ultrastructural abnormalities of the dentin matrix from DGI-I affected patients corresponded to a different expression of some of the examined proteins: in particular CS was less expressed and type VI collagen was more expressed in specimens from DGI-I affected patients than in sound primary teeth, respectively. No significant difference was detected in the labeling of type I collagen and the NCPs DMP 1, OPN and BGN between normal and DGI-I affected dentin. Our analysis focused on the primary teeth exfoliated by DGI-I affected patients since the primary dentition is usually more affected by DGI than the permanent teeth. ${ }^{1}$ Interestingly, primary dentin obtained by DGI-I affected patients was poor of dentinal tubules and showed dysplastic dentin, characterized by sparse and coarse collagen fibrils, which resemble more the predentin than the dentin typical features. ${ }^{10}$

As a dentin precursor, predentin is mineralized when apatite crystals are deposited within and around collagen fibrils. ${ }^{11}$ This process requires mechanisms that control the site and rate of apatite formation. Although the mechanisms that control mineralization are largely unknown, NCPs in dentin have been proposed to be critical for this process during dentinogenesis. ${ }^{7,11-13}$ We may speculate that the abnormal distribution of NCPs within the dentin matrix we assayed in DGI-I affected patients may also affect the mineralization process, leading to the suboptimally mineralized areas that characterize DGI-I. ${ }^{14}$ This lack of mineralization has been previously characterized as bone fragility for patients affected by osteogenesis imperfecta and was also extensively reported as defective dentin calcification in teeth affected by DGI-I, ${ }^{15-18}$ that wear more eas- ily and excessively compared to normal teeth. ${ }^{14,19,20}$

It is well known that identifying and immunolabeling type I collagen fibrils within mineralized tissues is challenging due to the low accessibility and low antigenicity. The labeling protocol employed in this study can be considered highly selective in identifying alterations in the protein epitopes as antigenicity of collagen revealed by its specific binding to a monoclonal antibody provides evidence of conservation of the epitope structure. ${ }^{4,21}$ Epitopes for type I collagen antibodies can be divided in relation to their ability to interact with the collagen structure in helical, central and termi- nal. Anti-helical type I collagen antibody (such as the one used in this study) recognizes the epitope based on three-dimensional structure, that is strictly related to the intact triple helix. Indeed this type of antibody binds only the native form of collagen type I, while no labeling occurs with denatured collagen molecules.

In previous studies on sound and carious human dentin, anti-type I collagen monoclonal antibody was used to assay the preservation of the collagen structure..$^{922-24}$ Interestingly, in the present study specimens harvested from DGI-I affected patients do not showed a reduced labeling for type I collagen compared to sound teeth. This labeling of the monoclonal anti-
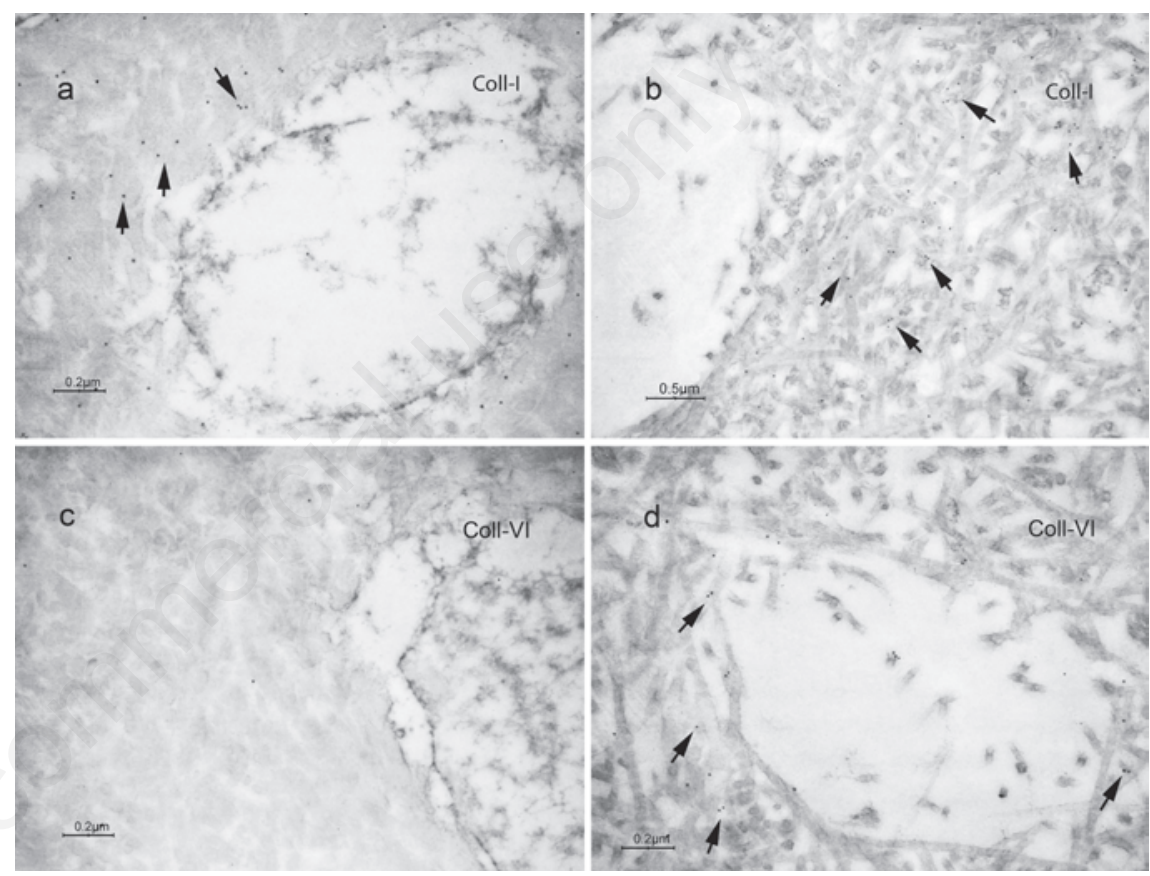

Figure 2. Transmission electron micrographs showing immunolabeling for type I collagen (Coll-I) in dentin of: a) sound exfoliated primary teeth; b) type I dentinogenesis imperfecta (DGI-I) affected teeth; c) immunolabeling for type VI collagen in sound dentin used as control; d) DGI-I affected dentin.

Table 1. Comparison of the number of gold particle-antibody complexes/ $\mathrm{m}^{2}$ after labeling for collagenous and non-collagenous proteins in dentin areas of sound primary teeth and teeth affected by type I dentinogenesis imperfecta.

\begin{tabular}{|c|c|c|c|}
\hline & $\begin{array}{l}\text { Sound primary teeth } \\
\qquad(n=20)\end{array}$ & $\begin{array}{l}\text { DGI-I affected teeth } \\
\qquad(n=20)\end{array}$ & P value \\
\hline \multicolumn{4}{|l|}{ Collagenous proteins } \\
\hline Type I collagen & $8.53 \pm 2.47$ & $10.44 \pm 4.92$ & 0.13 \\
\hline Type VI collagen & $4.68 \pm 0.15$ & $11.83 \pm 3.56$ & $<0.001^{*}$ \\
\hline \multicolumn{4}{|l|}{ Non collagenous proteins } \\
\hline Chondroitin sulphate & $8.98 \pm 1.81$ & $1.58 \pm 0.61$ & $<0.001^{*}$ \\
\hline Dentin matrix protein 1 & $21.93 \pm 5.65$ & $20.32 \pm 6.17$ & 0.22 \\
\hline Osteopontin & $6.48 \pm 1.77$ & $7.73 \pm 2.59$ & 0.083 \\
\hline Biglycan & $6.34 \pm 0.94$ & $2.30 \pm 0.31$ & 0.071 \\
\hline
\end{tabular}

DGI-I, type I dentinogenesis imperfecta. All values are expressed as means and standard deviations (SD). *Statistical difference at $\mathrm{P}<0.05$. 
type I collagen (clone COL 1) seems not to be affected by the well-known mutations observed in DGI-I, involving either of the two genes encoding type I collagen. ${ }^{25}$

Whereas weak in normal teeth, staining for type VI collagen was moderately present in dentin from DGI-affected patients. These findings confirm a previous study in which positive reactivity for collagen $\mathrm{VI}$ in the dentin of primary teeth affected by both type I DGI (associated with OI) and type II DGI. ${ }^{6}$ Labeling of type VI collagen in our specimens was similar to the one observed by Waltimo et al., which reported that the gold particles were often single, attached to non-striated material with a low electron density and also seen intratubularly. ${ }^{6}$ Interestingly, the reported lack of mineralization of the dentin matrix obtained by patients affected by DGI-I $\mathrm{I}^{14,19,20}$ is not clearly supported by the labeling detected for the major NCPs proteins implicated in the mineralization process such as DMP-1 and OPN (that were not significantly different between sound and affected primary teeth), whereas there were significant decrease only of CS expression in the DGI-I affected specimens compared to the normal dentin. Therefore, the main evidences are based on morphological changes and specific features that DGI-I affected specimens present: collagen fibrils in sound dentin showed opaque cross-striations, while collagen fibrils in DGI-dentin showed clear cross-striations. Noteworthy is that the present report for the first time quantify the presence of some of the collagenous and NCPs present indentin. Indeed, there are no reports examining the role of NCPs in type I DGI, whereas, for instance, dentin sialophosphoprotein (DSPP) has been previously investigated. ${ }^{26} \mathrm{~A}$ correlation between the defective cleavage of DSPP into DPP, in types II and III DGI, has been assayed whereas no clear correlation have been found between type I DGI and other enzymes cleaving the major NCPs proteins of dentin ECM. ${ }^{26}$ A recent paper has pointed out that many similarities exist between gene and protein structures of DSPP and DMP- $1{ }^{27}$ Both DSPP and DMP-1 contribute to hard tissue mineralization and DMP1 plays a regulatory role in dentin mineralization and can also function as a signaling molecule. ${ }^{28}$ In fact, a study characterizing DMP-1 null mice, clearly demonstrated that DMP-1 is required for dentin mineralization and that DSPP can be directly or indirectly controlled by DMP-1. ${ }^{12,29}$ Moreover, Chaussain et al., investigated the potential cleavage of DMP-1 by MMP-2 to release biologically active peptides. ${ }^{30}$ MMP- 2 is a predominant protease in the dentin matrix that plays a prominent role in tooth formation and extracellular matrix degradation. ${ }^{31}$ DMP1, both in the recombinant form and in its native state within the dentin matrix, was shown to be a substrate for MMP-2. ${ }^{30}$ Similarly, DMP-1 has been showed to be a possible substrate also for MMP-9. ${ }^{32}$ Future studies may focus on the expression of MMP-2 nor MMP-9 to clarify their role in the DGI-I disease and to further analyze the expression of the major NCPs and correlated MMPs in carious tissues of DGI-I affected teeth. ${ }^{33,34}$

Small leucine-rich PGs, including chondroitin 4/6 sulphate (CS)-rich decorin and BGN, have some important functional implications in collagen assembly of predentin. ${ }^{9}$ In
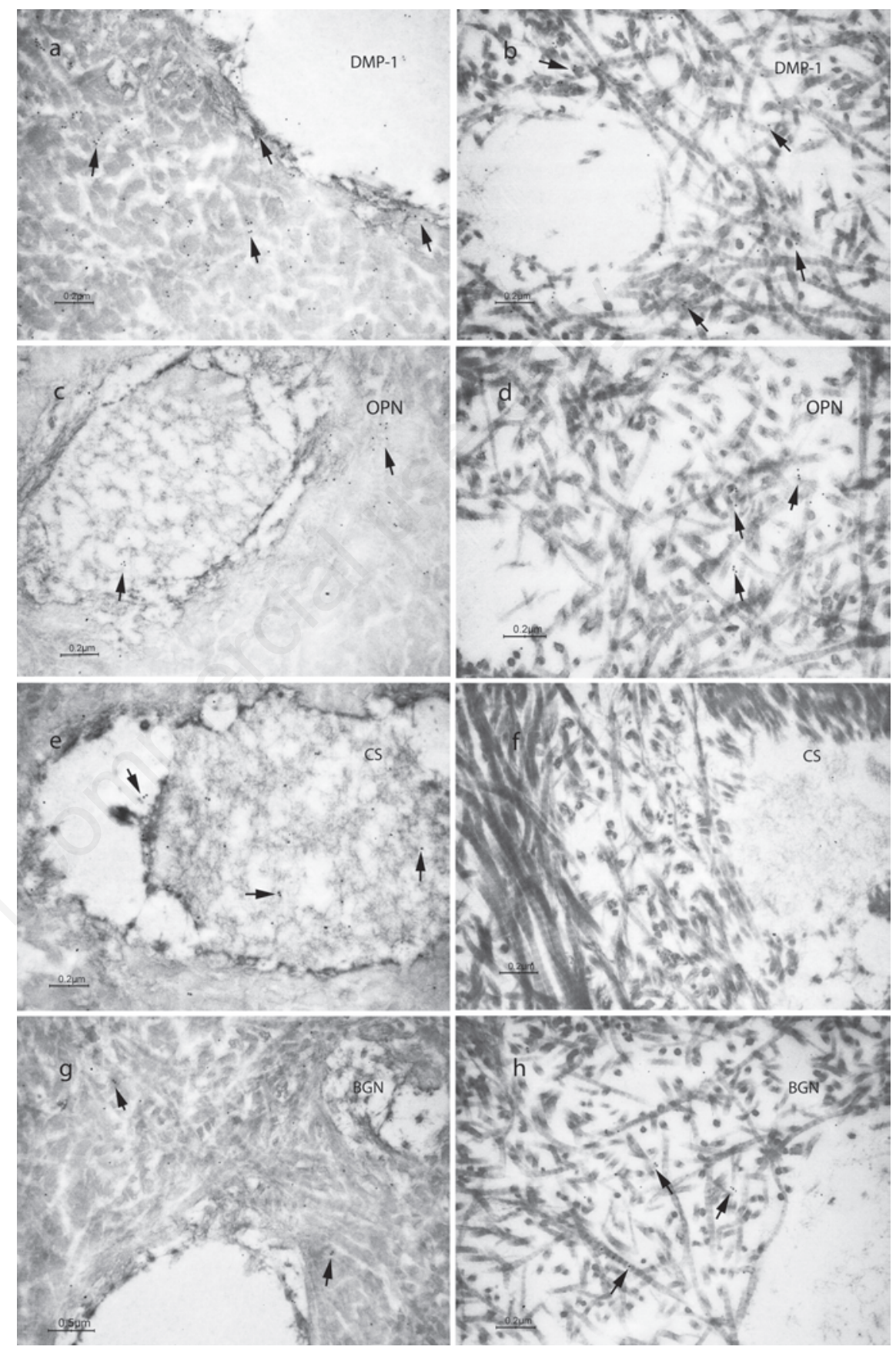

Figure 3. Transmission electron micrographs showing immunolabelig for: a) Dentin matrix protein 1 (DMP-1) in dentin of sound primary teeth used as controls; b) DMP-1 in dentin of type I dentinogenesis imperfecta (DGI-I) affected teeth; c) osteopontin (OPN) in sound dentin; d) OPN in DGI-I affected dentin; e) chondroitin sulphate (CS) in sound dentin; f) CS in DGI-I affected dentin; g) biglycan (BGN) in sound dentin; h) BGN in DGI-I affected dentin. 
particular, the suggested role of BGN is to regulate the growth and proliferation of mineral crystals and has been usually found more abundantly in predentin than in mineralized dentin, in which was generally localized in the mineralization front and within the dentinal tubules. ${ }^{8}$ The weak labeling revealed in DGI-I affected specimens for both CS and BGN (which was significantly weaker only for CS) may suggest that the defective unmineralized dentin does not present the same features of normal predentin, in which increasing of BGN was expected. These data are in partial agreement with the study by Ye et al., in which DMP1 null mice, characterized by dentin hypomineralization and expanded pulp cavities, showed no increasing of BGN production. ${ }^{12}$

In conclusion, although regulatory mechanisms for the expression of NCPs have not been fully elucidated, the present study correlates morphological alteration of dentin from patients affected by type I DGI with immunocytochemical findings, helping to elucidate the ultrastructural changes observed in dentin defects (currently classified as distinct entities). This may be a contribution to understand the pathogenesis of different types of heritable dentin defects as well as aid in early diagnosis of these diseases. Further studies related to the complicated interactions between the extracellular matrix macromolecules of dentin obtained by DGI-I affected patients are needed to fully clarify biochemical alterations that lead to deficient dentin formation.
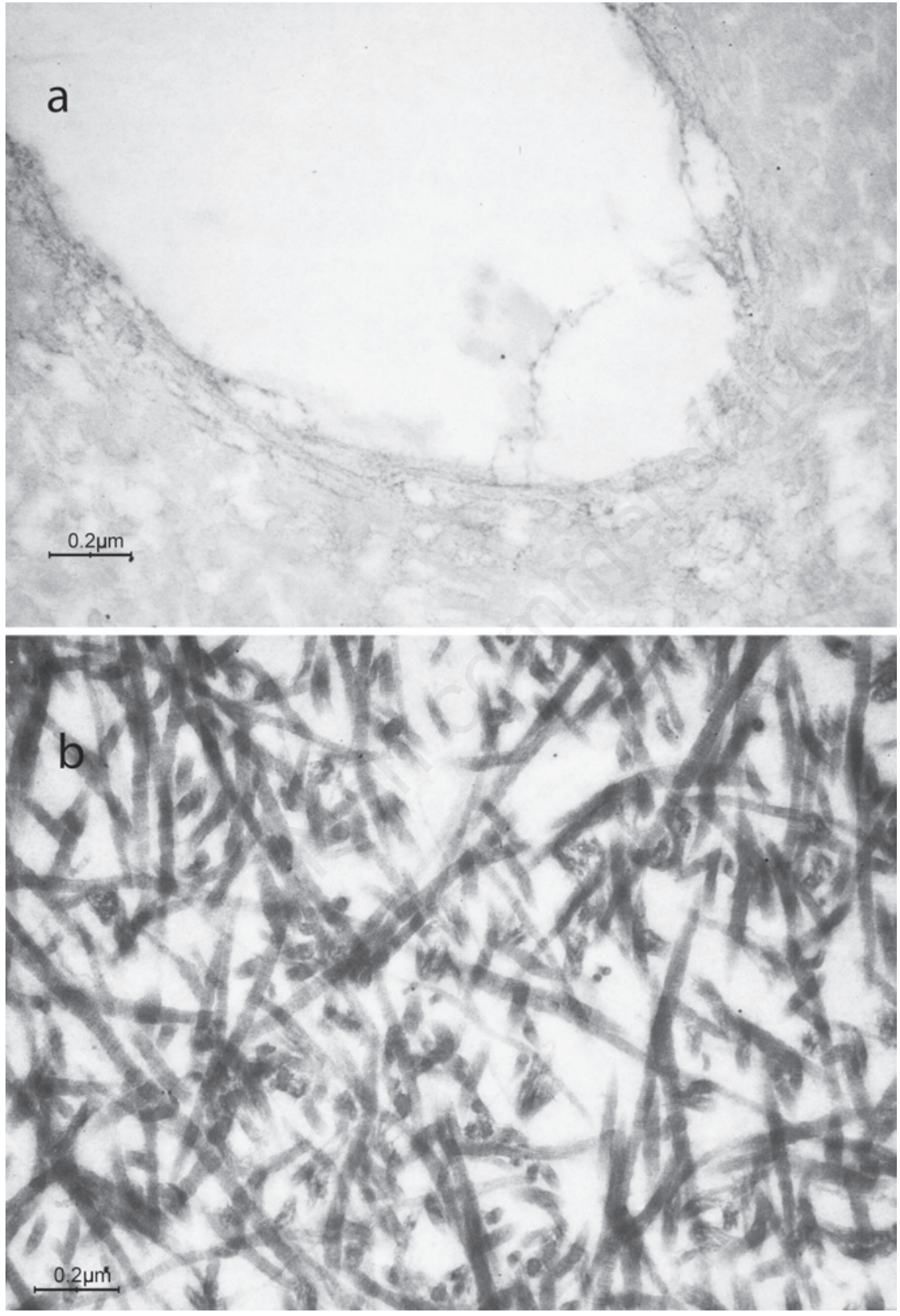

Figure 4. Representative images of the negative controls in dentin specimens of a) sound primary teeth; b) type I dentinogenesis imperfecta affected teeth.

\section{References}

1. O'Connell AC, Marini JC. Evaluation of oral problems in an osteogenesis imperfecta population. Oral Surg Oral Med Oral Pathol Oral Radiol Endod 1999;87:189-96.

2. Lukinmaa PL, Vaheri A. ED-A region-containing isoform of cellular fibronectin is present in dentin matrix in dentinogenesis imperfecta associated with osteogenesis imperfecta. J Dent Res 1994;73:1187-96.

3. Shields ED, Bixler D, el-Kafrawy AM. A proposed classification for heritable human dentine defects with a description of a new entity. Arch Oral Biol 1973;18:543-53.

4. Waltimo J, Ranta H, Lukinmaa PL. Ultrastructure of dentin matrix in heritable dentin defects. Scanning Microsc 1995;9:185-97; discussion 197-8.

5. Ranta H, Lukinmaa PL, Waltimo J. Heritable dentin defects: nosology, pathology, and treatment. Am J Med Genet 1993;45:193-200.

6. Waltimo J, Risteli L, Risteli J, Lukinmaa PL. Altered collagen expression in human dentin: increased reactivity of type III and presence of type VI in dentinogenesis imperfecta, as revealed by immunoelectron microscopy. J Histochem Cytochem 1994;42:1593-601.

7. Orsini G, Ruggeri A, Mazzoni A, Nato F, Manzoli L, Putignano A, et al. A review of the nature, role and function of dentin non-collagenous proteins: Part 1: proteoglycans and glycoproteins. Endodontic Topics 2012;21:1-18.

8. Orsini G, Ruggeri A, Jr., Mazzoni A, Papa V, Mazzotti G, Di Lenarda R, et al. Immunohistochemical identification of decorin and biglycan in human dentin: a correlative field emission scanning electron microscopy/transmission electron microscopy study. Calcif Tissue Int 2007; 81:39-45.

9. Orsini G, Ruggeri A Jr., Mazzoni A, Papa V, Piccirilli M, Falconi $M$, et al. Immunohistochemical identification of type I and type III collagen and chondroitin sulphate in human pre-dentine: a correla- 
tive FEI-SEM/TEM study. Int Endod J 2007;40:669-78.

10. Kim JW, Simmer JP. Hereditary dentin defects. J Dent Res 2007;86:392-9.

11. Butler WT, Ritchie H. The nature and functional significance of dentin extracellular matrix proteins. Int J Dev Biol 1995;39: 169-79.

12. Ye L, MacDougall M, Zhang S, Xie Y, Zhang J, Li Z, et al. Deletion of dentin matrix protein-1 leads to a partial failure of maturation of predentin into dentin, hypomineralization, and expanded cavities of pulp and root canal during postnatal tooth development. J Biol Chem 2004;279:19141-8.

13. Ruggeri A, Orsini G, Mazzoni A, Nato F, Papa $\mathrm{V}$, Piccirilli M, et al. Immunohistochemical and biochemical assay of versican in human sound predentine/dentine matrix. Eur $\mathrm{J}$ Histochem 2009;53:125-33.

14. Tsai CL, Lin YT, Lin YT. Dentinogenesis imperfecta associated with osteogenesis imperfecta: report of two cases. Chang Gung Med J 2003;26:138-43.

15. Salvolini E, Di Giorgio R, Caselli E, De Florio L. [Dentinogenesis imperfecta. Scanning electron microscopic study and microanalysis].[Article in Italian]. Minerva Stomatol 1999;48:87-92.

16. Majorana A, Bardellini E, Brunelli PC, Lacaita M, Cazzolla AP, Favia G. Dentinogenesis imperfecta in children with osteogenesis imperfecta: a clinical and ultrastructural study. Int $\mathrm{J}$ Paediatr Dent 2010;20:112-8.

17. Lukinmaa PL, Ranta H, Ranta K, Kaitila I. Dental findings in osteogenesis imperfecta: I. Occurrence and expression of type I dentinogenesis imperfecta. J Craniofac Genet Dev Biol 1987;7:115-25.

18. Kerebel B, Daculsi G, Menanteau J,
Kerebel LM. The inorganic phase in dentinogenesis imperfecta. J Dent Res 1981;60:1655-60.

19. Stephen LX, Beighton P. Dental management of severe dentinogenesis imperfecta in a mild form of osteogenesis imperfecta. J Clin Pediatr Dent 2002;26:131-6.

20. Rios D, Vieira AL, Tenuta LM, Machado MA. Osteogenesis imperfecta and dentinogenesis imperfecta: associated disorders. Quintessence Int 2005;36:695-701.

21. Willingham MC. Conditional epitopes. is your antibody always specific? J Histochem Cytochem 1999;47:1233-6.

22. Breschi L, Gobbi P, Mazzotti G, Falconi M, Ellis TH, Stangel I. High resolution SEM evaluation of dentin etched with maleic and citric acid. Dent Mater 2002;18:26-35.

23. Breschi L, Perdigao J, Gobbi P, Mazzotti G, Falconi M, Lopes M. Immunocytochemical identification of type I collagen in acidetched dentin. J Biomed Mater Res A 2003;66:764-9.

24. Suppa P, Ruggeri A, Tay FR, Prati C, Biasotto M, Falconi M et al. Reduced antigenicity of type I collagen and proteoglycans in sclerotic dentin. J Dent Res 2006;85:133-7.

25. Barron MJ, McDonnell ST, Mackie I, Dixon MJ. Hereditary dentine disorders: dentinogenesis imperfecta and dentine dysplasia. Orphanet J Rare Dis 2008;3:31.

26. Tsuchiya S, Simmer JP, Hu JC, Richardson AS, Yamakoshi F, Yamakoshi Y. Astacin proteases cleave dentin sialophosphoprotein (Dspp) to generate dentin phosphoprotein (Dpp). J Bone Miner Res 2011;26:220-8.

27. Suzuki S, Haruyama N, Nishimura F, Kulkarni AB. Dentin sialophosphoprotein and dentin matrix protein-1: Two highly phosphorylated proteins in mineralized tissues. Arch Oral Biol 2012;57:1165-75.

28. Orsini G, Ruggeri A, Mazzoni A, Nato F, Falconi M, Putignano A, et al. Immunohistochemical localization of dentin matrix protein 1 in human dentin. Eur $\mathrm{J}$ Histochem 2008;52:215-20.

29. Teti G, Salvatore V, Ruggeri A, Manzoli L, Gesi M, Orsini G, et al. In vitro reparative dentin: a biochemical and morphological study. Eur J Histochem 2013;57:e23.

30. Chaussain C, Eapen AS, Huet E, Floris C, Ravindran S, Hao J, et al. MMP2-cleavage of DMP1 generates a bioactive peptide promoting differentiation of dental pulp stem/progenitor cell. Eur Cell Mater 2009; 18:84-95.

31. Orsini G, Mazzoni A, Orciani M, Putignano A, Procaccini M, Falconi M, et al. Matrix metalloproteinase-2 expression induced by two different adhesive systems on human pulp fibroblasts. J Endod 2011; 37:1663-7.

32. Karadag A, Fedarko NS, Fisher LW. Dentin matrix protein 1 enhances invasion potential of colon cancer cells by bridging matrix metalloproteinase-9 to integrins and CD44. Cancer Res 2005;65:11545-52.

33. Martini D, Trirè A, Breschi L, Mazzoni A, Orsini G, Teti G, et al. Dentin matrix protein 1 and dentin sialophosphoprotein in human sound and carious teeth: an immunohistochemical and colorimetric assay. Eur J Histochem 2013;57:e32.

34. Loreto C, Galanti C, Musumeci G, Rusu MC, Leonardi R. Immunohistochemical analysis of matrix metalloproteinase-13 in human caries dentin. Eur J Histochem 2014;58:2318. 